\title{
Optimal blood pressure during cardiopulmonary bypass defined by cerebral autoregulation monitoring
}

\author{
Daijiro Hori, MD, ${ }^{a}$ Yohei Nomura, MD, ${ }^{a}$ Masahiro Ono, MD, ${ }^{b}$ Brijen Joshi, MD, ${ }^{c}$ Kaushik Mandal, MD, ${ }^{a}$ \\ Duke Cameron, MD, ${ }^{\mathrm{a}}$ Masha Kocherginsky, $\mathrm{PhD},{ }^{\mathrm{d}}$ and Charles W. Hogue, $\mathrm{MD}^{\mathrm{e}}$
}

\section{ABSTRACT}

Objectives: We sought to define the lower and upper limits of cerebral blood flow autoregulation and the optimal blood pressure during cardiopulmonary bypass. We further sought to identify variables predictive of these autoregulation end points.

Methods: Cerebral autoregulation was monitored continuously with transcranial Doppler in 614 patients during cardiopulmonary bypass enrolled in 3 investigations. A moving Pearson's correlation coefficient was calculated between cerebral blood flow velocity and mean arterial pressure to generate the variable mean velocity index. Optimal mean arterial pressure was defined as the mean arterial pressure with the lowest mean velocity index indicating the best autoregulation. The lower and upper limits of cerebral blood flow autoregulation were defined as the mean arterial pressure at which mean velocity index was increasingly pressure passive (ie, mean velocity index $\geq 0.4$ ) with declining or increasing blood pressure, respectively.

Results: The mean ( \pm standard deviation) lower and upper limits of cerebral blood flow autoregulation, and optimal mean arterial pressure were $65 \pm 12 \mathrm{~mm} \mathrm{Hg}, 84 \pm 11 \mathrm{~mm} \mathrm{Hg}$, and $78 \pm 11 \mathrm{~mm} \mathrm{Hg}$, respectively, after adjusting for study enrollment. In $17 \%$ of patients, though, the lower limit of cerebral autoregulation was above this optimal mean arterial pressure, whereas in $29 \%$ of patients the upper limit of autoregulation was below the population optimal mean arterial pressure. Variables associated with optimal mean arterial pressure based on multivariate regression analysis were nonwhite race (increased $2.7 \mathrm{~mm} \mathrm{Hg}$; $P=.034$ ), diuretics use (decreased $1.9 \mathrm{~mm} \mathrm{Hg} ; P=.049$ ), prior carotid endarterectomy (decreased $5.5 \mathrm{~mm} \mathrm{Hg} ; P=.019$ ), and duration of cardiopulmonary bypass (decreased 1.28 per 60 minutes of cardiopulmonary bypass). The product of the duration and magnitude that mean arterial pressure during cardiopulmonary bypass was below the lower limit of cerebral autoregulation was associated with

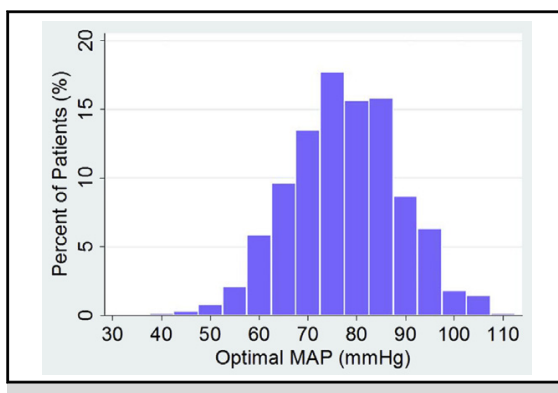

Range of optimal MAPs.

\section{Central Message}

We provide evidence for optimal MAP during $\mathrm{CPB}$ based on cerebral autoregulation monitoring.

\section{Perspective}

There is no consensus on optimal MAP during CPB. Cerebral autoregulation monitoring in 614 patients during $\mathrm{CPB}$ showed that optimal MAP for patients was $78 \pm 11 \mathrm{~mm} \mathrm{Hg}$. However, this target will not be accurate in $17 \%$ to $29 \%$ of patients. Real-time monitoring of autoregulation may better ensure perfusion during $\mathrm{CPB}$

See Editorial Commentary page 1599.

See Editorial page 1588. the risk for stroke $(P=.02)$.

Conclusions: Real-time monitoring of autoregulation may improve individualizing mean arterial pressure during cardiopulmonary bypass and improving patient outcomes. (J Thorac Cardiovasc Surg 2017;154:1590-8)

\footnotetext{
From the a Division of Cardiac Surgery, Department of Surgery, and ${ }^{\mathrm{c}}$ Department of Anesthesiology and Critical Care Medicine, The Johns Hopkins University School of Medicine, Baltimore, Md; ${ }^{b}$ Department of Cardiac Surgery, The Texas Heart Institute, Houston, Tex; ${ }^{\mathrm{d}}$ Department of Preventive Medicine, and ${ }^{\mathrm{e}}$ Department of Anesthesiology and the Bluhm Cardiovascular Institute, Northwestern University Feinberg School of Medicine, Chicago, Ill

This work was supported in part by Grant-in-Aid Number 103363 from the MidAtlantic Affiliate of the American Heart Association and Grant R01HL092259 from the National Institutes of Health to C.W.H.

Clinical Trial: NCT00981474, NCT00769691
}

Read at the 96th Annual Meeting of The American Association for Thoracic Surgery, Baltimore, Maryland, May 14-18, 2016.

Received for publication March 31, 2016; revisions received March 29, 2017; accepted for publication April 10, 2017.

Address for reprints: Charles W. Hogue, MD, The Department of Anesthesiology, Northwestern University Feinberg School of Medicine, 251 East Huron St, Chicago, IL 60611 (E-mail: charles.hogue@northwestern.edu). $0022-5223 / \$ 36.00$

Copyright (C) 2017 by The American Association for Thoracic Surgery http://dx.doi.org/10.1016/j.jtcvs.2017.04.091 

Abbreviations and Acronyms
$\mathrm{ABP}=$ arterial blood pressure
$\mathrm{CBF}=$ cerebral blood flow
$\mathrm{CPB}=$ cardiopulmonary bypass
LLA $=$ lower limit of autoregulation
$\mathrm{MAP}=$ mean arterial pressure
$\mathrm{Mx}=$ mean velocity index
$\mathrm{SD}=$ standard deviation
$\mathrm{TCD}=$ transcranial Doppler
$\mathrm{ULA}=$ upper limit of autoregulation

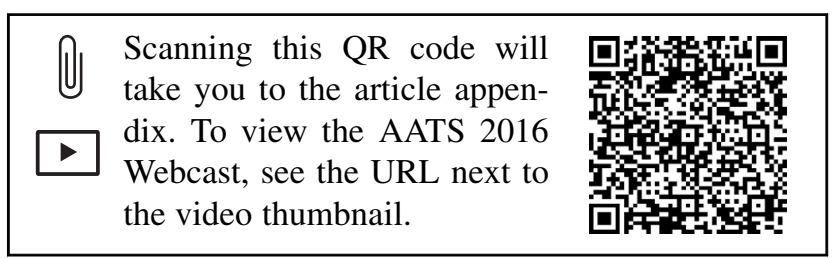

Since its introduction on May 6, 1953, by J. H. Gibbons, Jr, cardiopulmonary bypass (CPB) has allowed surgical teams to improve survival and quality of life for patients with life-threatening cardiovascular disease. ${ }^{1-3}$ Despite multiple technologic and patient management advances in the ensuing 60 years, controversy remains regarding the appropriate mean arterial pressure (MAP) for patients during $\mathrm{CPB}$, with no definition of optimal MAP universally accepted. ${ }^{4}$ The guiding principle of blood pressure management during $\mathrm{CPB}$ is that cerebral blood flow $(\mathrm{CBF})$ autoregulation must remain functional during $\mathrm{CPB}$ when $\alpha$-stat $\mathrm{pH}$ management is used. ${ }^{4-6}$ Consequently, a MAP as low as $50 \mathrm{~mm} \mathrm{Hg}$, and even transiently lower, is often believed to be acceptable during CPB because CBF will not be compromised. ${ }^{5,7}$ However, cerebral autoregulation might be impaired by many conditions that are prevalent in patients with coronary artery disease. ${ }^{8,9}$ Indeed, neurologic complications, including stroke and acute cognitive disorders, affect $1 \%$ to $2 \%$ and up to $20 \%$ to $40 \%$ of patients, respectively, after cardiac surgery. ${ }^{4,10}$ Many such complications might be explained by cerebral hypoperfusion. ${ }^{11-14}$

Cerebral autoregulation now can be monitored at the bedside by continuously calculating the correlation coefficient between slow-wave (ie, every 20 seconds to 3 minutes) changes in CBF velocity (measured with transcranial Doppler [TCD]) and MAP. ${ }^{15-17}$ By using these methods in patients undergoing $\mathrm{CPB}$, our group has reported that MAP at the lower limit of autoregulation (LLA) is broad (40$90 \mathrm{~mm} \mathrm{Hg}$ ) and difficult to predict by patient demographics and other preoperative factors. ${ }^{16}$ We have further found that the magnitude and duration that MAP is below the LLA during CPB is associated with major morbidity and mortality postoperatively. ${ }^{18,19}$ However, simply increasing MAP targets during CPB may be associated with other adverse postoperative outcomes, as we have found that blood pressure excursions above the upper limit of autoregulation (ULA) during CPB are associated with postoperative delirium. ${ }^{20}$ Together, these studies suggest that guiding hemodynamics to ensure cerebral perfusion within the autoregulation range may be better for patient outcome than choosing these targets empirically. In our investigations, we have observed that as many as $20 \%$ of patients will not have a clear LLA because of a pattern of impaired autoregulation. ${ }^{21}$ In these situations, though, an optimal MAP usually is still observed at which autoregulation is best. Maintaining cerebral perfusion pressure in the optimal autoregulation range is associated with improved outcomes for patients with traumatic brain injury, supporting the potential clinical role of autoregulation monitoring. ${ }^{22}$ Our prior investigations did not have an adequate sample size to determine with high precision the range of optimal MAP for patients undergoing cardiac surgery with $\mathrm{CPB}$, and we did not evaluate MAP with respect to ULA.

Despite growing data supporting a role for customized MAP targets based on autoregulation monitoring in patients undergoing cardiac surgery, the latter methods remain a research tool. The goal of this study was to expand on prior investigations of CBF autoregulation to provide guidance about optimal MAP to clinicians who care for patients undergoing cardiac surgery. We sought to define the LLA and ULA of CBF autoregulation and optimal blood pressure during $\mathrm{CPB}$. We further sought to identify variables predictive of these autoregulation end points.

\section{MATERIALS AND METHODS}

From April 2008 to April 2015, 614 patients undergoing cardiac surgery at The Johns Hopkins Hospital were enrolled in 2 completed trials and 1 ongoing prospective trial that evaluated cerebral autoregulation monitoring with TCD (NCT00981474, NCT00769691). ${ }^{23,24}$ A flow diagram of the patients included in this study is shown in Figure 1. Enrollment in the largest of the 3 studies was limited to patients at high risk for neurologic complications as determined by the Johns Hopkins stroke and encephalopathy risk score. ${ }^{25}$ Patients undergoing circulatory arrest were excluded. All procedures received the approval of the Institutional Review Board of The Johns Hopkins Medical Institutions, and all patients provided written informed consent. A total of 346 patients included in this analysis were enrolled in a study that included preoperative TCD examination by a trained vascular technologist. As part of that protocol, patients in whom a temporal window for TCD monitoring was not present were excluded from subsequent intraoperative monitoring.

\section{Hemodynamic Management and Anesthesia}

General anesthesia was induced and maintained with midazolam, fentanyl, and isoflurane, and pancronium or vecuronium was administered for skeletal muscle relaxation. Before $\mathrm{CPB}$, heparin was administered to achieve an activated clotting time greater than 480 seconds. The CPB flow was nonpulsatile and maintained with a target of 2.0 to $2.4 \mathrm{~L} / \mathrm{min} / \mathrm{m}^{2}$. Arterial pressure was monitored via a radial artery 


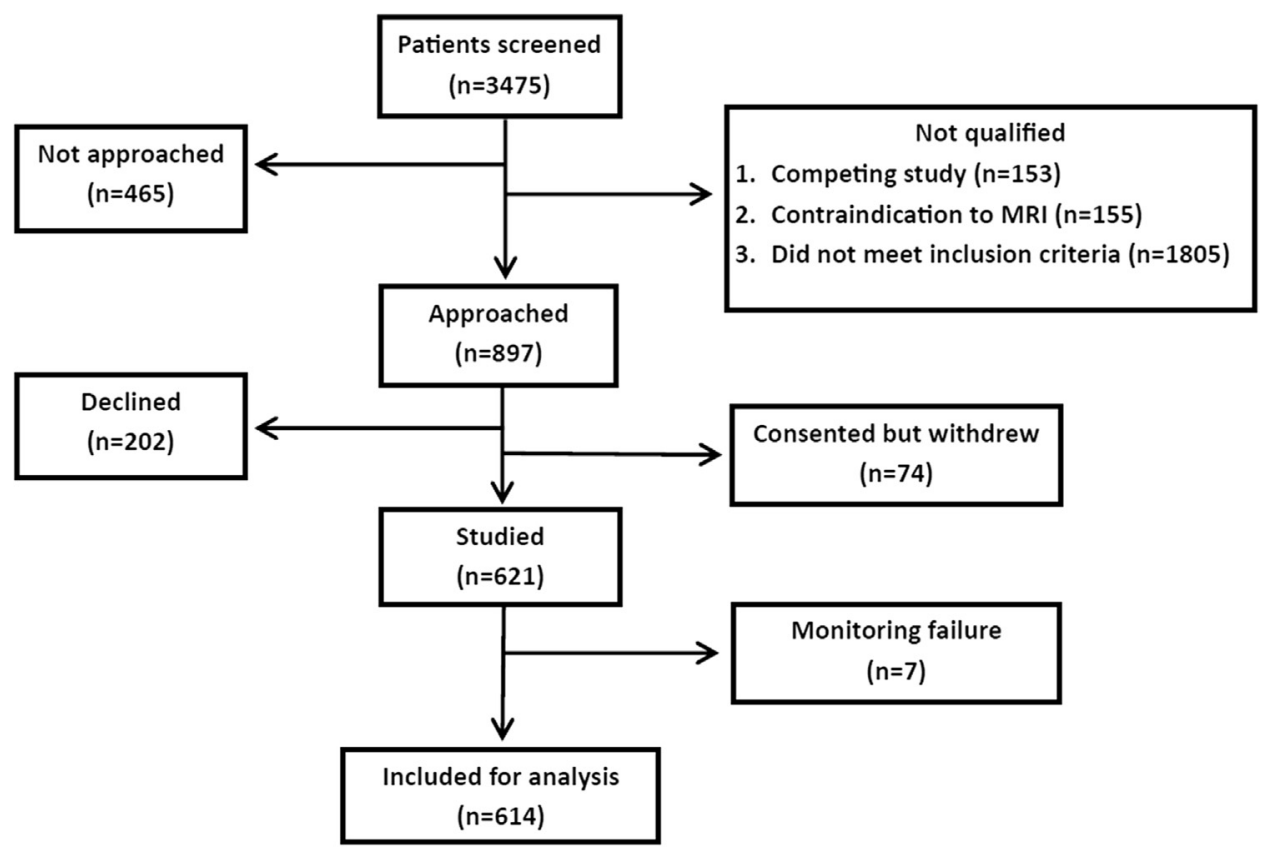

FIGURE 1. Flow diagram of the patients enrolled in the study and included in this analysis.

catheter and was controlled by adjusting CPB flow and the administration of vasoactive medications. The patients were managed with alpha-stat $\mathrm{pH}$ management. Normocarbia was ensured with a continuous in-line arterial blood gas monitor that was calibrated hourly. Protamine was administered to reverse the effects of heparin after separation from CPB.

\section{Transcranial Doppler-Based Autoregulation Monitoring}

After patients were anesthetized and intubated via the trachea, TCD monitoring (DWL, Compumedics DWL, El Paso, Tex) of the right and left middle cerebral arteries was initiated by positioning two $2.5-\mathrm{MHz}$ transducers fitted on a headband over the temporal bone. Depth of insonation was varied between 35 and $52 \mathrm{~mm}$ until representative spectral CBF flow was identified. Analog arterial pressure and TCD signals from the operating room hemodynamic monitor were processed with a data-acquisition module (DT9800, Data Translation Inc, Marlboro, Mass) and then analyzed by
ICM+ software (University of Cambridge, Cambridge, United Kingdom) as described previously. ${ }^{15,26-28}$ The signals were filtered as nonoverlapping 10 -second mean values that were time-integrated, which is equivalent to having a moving average filter with a 10 -second time window and resampling at $0.1 \mathrm{~Hz}$, eliminating high-frequency components caused by respiration and pulse waveforms. Additional high-pass filtering was applied with a DC cutoff set at $0.003 \mathrm{~Hz}$. A continuous, moving Pearson's correlation coefficient between changes in MAP and mean middle cerebral artery blood flow velocity was calculated to render the variable mean velocity index (Mx). Consecutive, average Mx values within a 10 -second window were collected as 30 data points to monitor each $\mathrm{Mx}$ in a 300-second window. More details of these methods are provided in Appendix E1. Mx approaches 1 when MAP is outside the limits of autoregulation, indicating pressure-passive CBF. In contrast, $\mathrm{Mx}$ approaches 0 or is negative when MAP is within the CBF autoregulation range. Average Mx values obtained during $\mathrm{CPB}$ were placed in $5 \mathrm{~mm} \mathrm{Hg}$ MAP bins. The LLA was defined as the MAP at which Mx increased to a value 0.4 or greater with declining blood pressure. Optimal

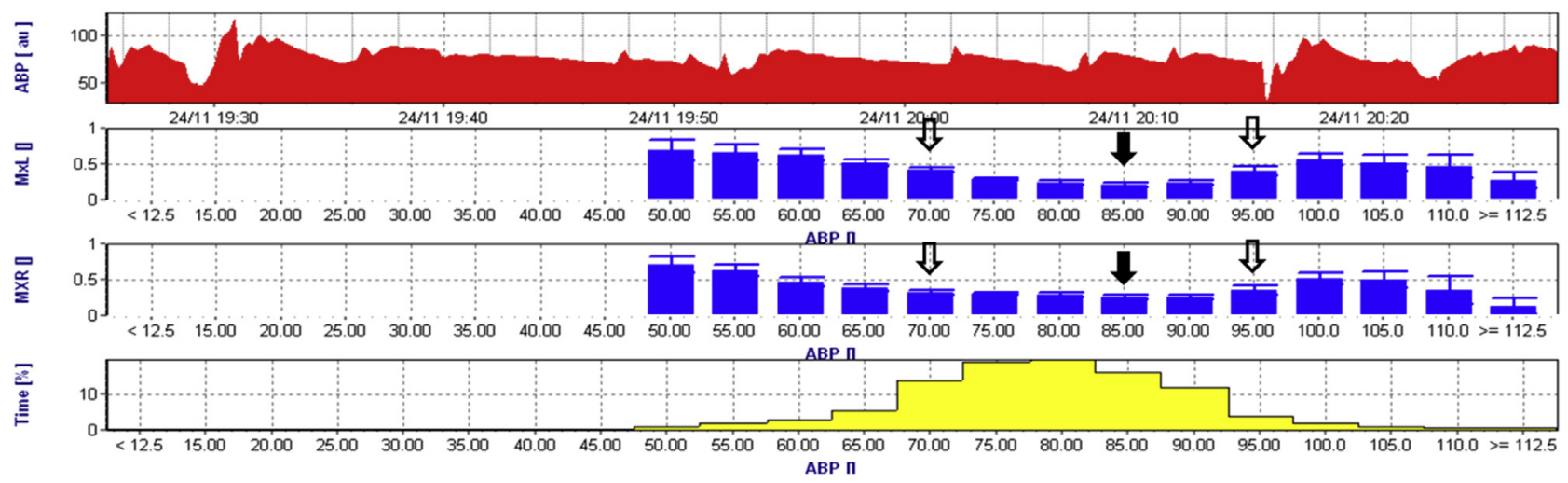

FIGURE 2. Representative graph of cerebral autoregulation monitoring by Mx during CPB. The top graph represents the time-series of $\mathrm{ABP}$, and the bottom bar-graph represents the percentage of the time of the recording spent at $5 \mathrm{~mm} \mathrm{Hg}$ bin. Optimal MAP (ABP) for the left and right side of the brain was defined as that MAP with the lowest Mx. LLA and ULA were defined as the MAP at which Mx reached 0.4. In this example, the optimal MAP is 85 mm $\mathrm{Hg}$ (black arrow) and the LLA and ULA are $70 \mathrm{~mm} \mathrm{Hg}$ and $95 \mathrm{~mm} \mathrm{Hg}$, respectively (black-outlined arrow). ABP, Arterial blood pressure. 
TABLE 1. Demographics and intraoperative data for the entire cohort, based on enrolled study

\begin{tabular}{|c|c|c|c|c|c|}
\hline Variable & $\begin{array}{c}\text { Entire cohort } \\
\qquad \mathbf{N}=617\end{array}$ & $\begin{array}{l}\text { Study } 1^{17} \\
N=183\end{array}$ & $\begin{array}{l}\text { Study } 2^{24} \\
N=105\end{array}$ & $\begin{array}{c}\text { Study } 3 \\
\mathbf{N}=\mathbf{3 2 6}\end{array}$ & $P$ value \\
\hline Age $(y)^{*}$ & $67.2 \pm 10.5$ & $64.6 \pm 11.3$ & $61.2 \pm 12.0$ & $70.7 \pm 8.0$ & $<.001$ \\
\hline Female gender & $160(26.1 \%)$ & $34(18.6 \%)$ & $29(27.6 \%)$ & $97(29.8 \%)$ & .021 \\
\hline White ethnicity $\dagger$ & $520(85.0 \%)$ & $165(90.2 \%)$ & $90(85.7 \%)$ & $265(81.8 \%)$ & .039 \\
\hline History of tobacco smoking & $280(45.6 \%)$ & $72(39.3 \%)$ & $45(42.9 \%)$ & $163(50.0 \%)$ & .056 \\
\hline COPD & $65(10.6 \%)$ & $18(9.8 \%)$ & $10(9.5 \%)$ & $37(11.3 \%)$ & .805 \\
\hline Diabetes & $247(40.2 \%)$ & $53(29.0 \%)$ & $37(35.2 \%)$ & $157(48.2 \%)$ & $<.001$ \\
\hline $\mathrm{CHF}$ & $106(17.3 \%)$ & $29(15.8 \%)$ & $25(23.8 \%)$ & $52(16.0 \%)$ & .15 \\
\hline Hypertension & $490(79.8 \%)$ & $131(71.6 \%)$ & $76(72.4 \%)$ & $283(86.8 \%)$ & $<.001$ \\
\hline Creatinine $(\mathrm{g} / \mathrm{dL})^{*}$ & $1.2 \pm 1.0$ & $1.2 \pm 1.2$ & $1.5 \pm 1.6$ & $1.1 \pm 0.3$ & .001 \\
\hline Preoperative eGFR* & $74.4 \pm 24.7$ & $77.3 \pm 25.8$ & $73.1 \pm 28.9$ & $73.2 \pm 22.4$ & .156 \\
\hline Preoperative mean blood pressure $(\mathrm{mm} \mathrm{Hg})^{*}$ & $93.5 \pm 13.3$ & $93.7 \pm 13.7$ & $91.9 \pm 14.0$ & $93.9 \pm 12.9$ & .39 \\
\hline Preoperative systolic blood pressure $(\mathrm{mm} \mathrm{Hg})^{*}$ & $136.2 \pm 21.2$ & $137.1 \pm 20.5$ & $132.9 \pm 22.7$ & $136.9 \pm 21.0$ & .198 \\
\hline Preoperative hemoglobin $(\mathrm{g} / \mathrm{dL})^{*}$ & $12.5 \pm 2.0$ & $12.7 \pm 2.0$ & $12.2 \pm 2.2$ & $12.5 \pm 2.0$ & .159 \\
\hline Angiotensin-converting enzyme inhibitors-I & $226(36.8 \%)$ & $58(31.7 \%)$ & $37(35.2 \%)$ & $131(40.2 \%)$ & .152 \\
\hline Statins & $317(51.7 \%)$ & $116(63.4 \%)$ & $62(59.0 \%)$ & $139(42.8 \%)$ & $<.001$ \\
\hline Aspirin & $441(71.8 \%)$ & $119(65.0 \%)$ & $66(62.9 \%)$ & $256(78.5 \%)$ & $<.001$ \\
\hline Beta-blocker & $379(61.7 \%)$ & $107(58.5 \%)$ & $59(56.2 \%)$ & $213(65.3 \%)$ & .137 \\
\hline $\mathrm{Ca}^{++}$channel blocker & $129(21.0 \%)$ & $26(14.2 \%)$ & $24(22.9 \%)$ & $79(24.2 \%)$ & .025 \\
\hline Nitrates & $107(17.4 \%)$ & $28(15.3 \%)$ & $12(11.4 \%)$ & $67(20.6 \%)$ & .067 \\
\hline Diuretics & $218(35.5 \%)$ & $42(23.0 \%)$ & $42(40.0 \%)$ & $134(41.1 \%)$ & $<.001$ \\
\hline Prior carotid endarterectomy & $23(3.7 \%)$ & $2(1.1 \%)$ & $5(4.8 \%)$ & $16(4.9 \%)$ & .078 \\
\hline Prior CVA & $57(9.3 \%)$ & $19(10.4 \%)$ & $5(4.8 \%)$ & $33(10.1 \%)$ & .214 \\
\hline Prior TIA & $33(5.4 \%)$ & $10(5.5 \%)$ & $1(1.0 \%)$ & $22(6.7 \%)$ & .072 \\
\hline Peripheral vascular disease & $89(14.5 \%)$ & $21(11.5 \%)$ & $10(.5 \%)$ & $58(17.8 \%)$ & .043 \\
\hline Coronary artery disease & $467(76.1 \%)$ & $143(78.1 \%)$ & $63(60.0 \%)$ & $261(80.1 \%)$ & $<.001$ \\
\hline CPB duration (min)* & $112.8 \pm 48.0$ & $116.58 \pm 43.1$ & $104.7 \pm 44.5$ & $113.4 \pm 51.4$ & .129 \\
\hline Aortic crossclamp duration $(\mathrm{min})^{*}$ & $69.2 \pm 32.0$ & $72.8 \pm 33.6$ & $57.1 \pm 32.2$ & $71.2 \pm 30.0$ & $<.001$ \\
\hline Average MAP (mm Hg)* & $73.7 \pm 8.1$ & $72.6 \pm 8.5$ & $72.0 \pm 8.4$ & $74.8 \pm 7.6$ & .001 \\
\hline Lowest hemoglobin $(\mathrm{g} / \mathrm{L})^{*}$ & $8.2 \pm 1.3$ & $8.3 \pm 1.3$ & $8.3 \pm 1.4$ & $8.1 \pm 1.3$ & .211 \\
\hline
\end{tabular}

COPD, Chronic obstructive pulmonary disease; $C H F$, congestive heart failure; $e G F R$, estimated glomerular filtration rate; $C V A$, cerebral vascular accident; TIA, transient ischemic attack; $C P B$, cardiopulmonary bypass; $M A P$, mean arterial pressure. *Data are provided as mean $\pm \mathrm{SD}$ for continuous variables that were normally distributed. $\dagger$ Nonwhite race group is predominantly African-Americans, with only 16 patients in study 3 reporting other race.

MAP was defined as that MAP at the lowest Mx indicating the best autoregulation. ${ }^{22}$ The ULA was defined as the MAP at which Mx increased to 0.4 or greater with increasing blood pressure. ${ }^{20}$ A representative autoregulation tracing obtained during CPB is shown in Figure 2. More details about the methods can be found in Appendix E1. We separately evaluated the LLA, ULA, and optimal MAP from the right and left Mx data. For the purpose of data analysis, we took the highest MAP to define the LLA and optimal MAP and the lowest MAP value for the ULA if there were discrepancies between cerebral hemispheres. We believe that this would be clinically the most applicable method when this type of monitoring becomes widespread. That is, the target MAP would be that which best ensures perfusion to the most compromised hemisphere while trying to avoid MAP greater than ULA.

\section{Sample Size Calculation}

The sample size was calculated with an estimation of optimal MAP that was based on CBF autoregulation end points collected previously from 225 patients undergoing cardiac surgery. ${ }^{16}$ In that study, average mean MAP at the LLA was $66 \mathrm{~mm} \mathrm{Hg}$, and the standard deviation (SD) was $12 \mathrm{~mm} \mathrm{Hg}$. On the basis of those data, we estimated that a sample size of 553 patients would provide a $1 \mathrm{~mm} \mathrm{Hg}$ margin of error in determining optimal MAP with a $95 \%$ confidence interval between 65 and $67 \mathrm{~mm} \mathrm{Hg}$.

\section{Data Analysis}

Complications after surgery were classified on the basis of definitions of the Society of Thoracic Surgery National Cardiac Surgery Database. Continuous variables are summarized as mean and SD. Normality assumption was checked, and non-normally distributed variables were log-transformed. Continuous variables were compared between groups using a $t$ test or linear regression. Categoric variables were analyzed using the chi-square test or Fisher exact test if frequencies were low. Linear regression models were used to examine the effects of predictors on continuous outcomes (eg, LLA, MAP), adjusting for study. Multiple linear regression was used to identify baseline predictors of MAP; the final model was chosen using Akaike Information Criterion-based backward selection 
TABLE 2. Optimal mean arterial blood pressure and mean arterial blood pressure at the lower limit of autoregulation and upper limit of autoregulation for the entire cohort and by study

\begin{tabular}{|c|c|c|c|c|c|}
\hline & $\begin{array}{c}\text { Entire cohort } \\
\qquad N=617\end{array}$ & $\begin{array}{c}\text { Study } 1^{17} \\
N=183 \\
\end{array}$ & $\begin{array}{l}\text { Study } 2^{24} \\
N=105\end{array}$ & $\begin{array}{l}\text { Study } 3 \\
\mathbf{N}=326\end{array}$ & $P$ value \\
\hline Optimal MAP (mean $\pm \mathrm{SD}, \mathrm{mm} \mathrm{Hg}$ ) & $78 \pm 11$ & $74 \pm 12$ & $75 \pm 10$ & $80 \pm 11$ & $<.001$ \\
\hline LLA (mm Hg) & $65 \pm 12$ & $63 \pm 11$ & $66 \pm 13$ & $66 \pm 12$ & .024 \\
\hline ULA (mm Hg) & $84 \pm 11$ & $81 \pm 10$ & $82 \pm 9$ & $86 \pm 12$ & .002 \\
\hline Patients who crossed LLA & $434(71 \%)$ & $141(77 \%)$ & $70(67 \%)$ & $223(68 \%)$ & .074 \\
\hline Patients who crossed ULA & $323(52 \%)$ & $102(56 \%)$ & $58(55 \%)$ & $163(50 \%)$ & .387 \\
\hline
\end{tabular}

The optimal MAP was defined as the MAP with the lowest Mx (see text). Data are listed as mean \pm SD or number (\%) of patients. MAP, Mean arterial pressure; $S D$, standard deviation; $L L A$, lower limit of autoregulation; $U L A$, upper limit of autoregulation.

from among baseline variables in Table 1, keeping demographics (age, gender, ethnicity, and smoking history) and study indicator in all models. Stability of the final model was checked using stepwise model selection strategies. Logistic regression models were used for binary outcomes (eg, CPB complications), adjusting for study. Analyses were performed using Stata version 14 (StataCorp LP, College Station, Tex).

\section{RESULTS}

Patient demographics and medical history are listed in Table 1. Predictably, demographic characteristics varied among the 3 studies. Table 2 presents the autoregulation data measured during CPB. An LLA during CPB was observed in $434(71 \%)$ of 614 patients, and a ULA was observed in 323 patients $(53 \%)$, whereas optimal MAP was observed in all patients. For these patients, the (mean $\pm \mathrm{SD}$ ) LLA was $65 \pm 12 \mathrm{~mm} \mathrm{Hg}$ and the ULA was $84 \pm 11 \mathrm{~mm} \mathrm{Hg}$. The optimal MAP was $78 \pm 12 \mathrm{~mm} \mathrm{Hg}$. The distribution of optimal MAP is shown in Figure 3. A pattern of impaired autoregulation (ie, $\mathrm{Mx}$ was $>0.4$ at all MAP) was observed in 98 patients $(16 \%)$. In 82 patients $(13 \%)$, an LLA was not observed, which may suggest that the normal fluctuations in MAP that occur during CPB never crossed the autoregulation threshold.

There was no relationship between patient age and the LLA, the optimal MAP, or the product of the magnitude

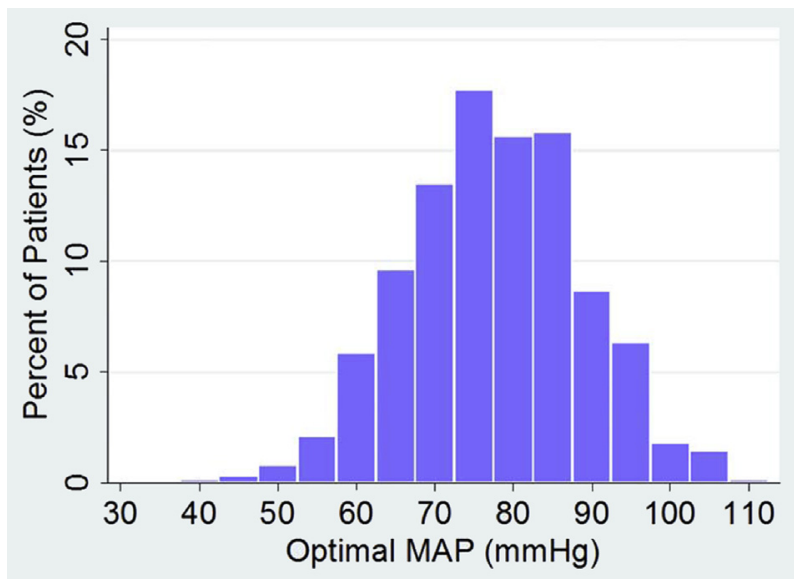

FIGURE 3. Distribution of optimal MAP for the entire cohort. MAP, Mean arterial pressure. and duration for which MAP was below the LLA (ie, the "severity" of MAP below LLA) based on linear regression models. The distribution of optimal MAP is shown in Figure 3. In $17 \%$ of patients, the LLA was above this optimal MAP, whereas in $29 \%$ of patients the ULA was below the population optimal MAP. Patients with $\mathrm{Mx}$ greater than 0.4 at all MAPs (98 patients) were excluded from the latter analysis because we were unable to determine their LLA or ULA. An individual whose LLA MAP is above that of the group could experience cerebral hypoperfusion if the MAP during CPB is maintained at the group optimal MAP. Conversely, a ULA below the population median value could result in cerebral hyperperfusion if MAP is kept at the group median value. Strokes occurred in 5\% of patients after surgery. The product of the magnitude and duration that MAP was less than LLA during CPB was associated with the risk of postoperative stroke $(P=.018)$.

Predictors of optimal MAP based on multivariate linear regression adjusting for study are listed in Table 3 . Nonwhite race, preoperative use of diuretic drugs, prior carotid endarterectomy, and duration of CPB were independently associated with optimal MAP during CPB. Optimal MAP was $2.73 \mathrm{~mm} \mathrm{Hg}$ higher $(P=.034)$ for nonwhite patients and $1.9 \mathrm{~mm} \mathrm{Hg}$ lower $(P=.049)$ for patients receiving diuretics. Optimal MAP was $5.5 \mathrm{~mm}$ $\mathrm{Hg}$ lower $(P=.019)$ for patients with a prior carotid endarterectomy and $1.28 \mathrm{~mm} \mathrm{Hg}$ lower per 60 minutes of CPB $(P=.22)$. No other factors were significantly associated with optimal MAP in the linear regression model. The model explained little of optimal MAP variability $\left(\mathrm{R}^{2}=0.1002\right)$.

\section{DISCUSSION}

In this study, we found that the MAP (mean $\pm \mathrm{SD}$ ) at the LLA during CPB was $65 \pm 12 \mathrm{~mm} \mathrm{Hg}$, the ULA was $84 \pm 11 \mathrm{~mm} \mathrm{Hg}$, and the optimal MAP was $78 \pm 11 \mathrm{~mm}$ $\mathrm{Hg}$. An LLA during CPB was observed in $434(71 \%)$ of 614 patients, and a ULA was observed in 323 patients (53\%), whereas optimal MAP was observed in all patients. Patient age, history of hypertension, and diabetes were not 
TABLE 3. Multiple regression model predicting optimal mean arterial pressure

\begin{tabular}{lrlr}
\hline \multicolumn{1}{c}{ Variable } & Estimate & \multicolumn{1}{c}{$\mathbf{9 5 \%}$ CI } & $\boldsymbol{P}$ value \\
\hline Study 1 vs 3 & -6.03 & $(-8.6$ to -3.9$)$ & $<.001$ \\
Study 2 vs 3 & -4.95 & $(-7.5$ to -2.4$)$ & $<.001$ \\
\hline Age & -0.02 & $(-0.1$ to 0.1$)$ & .650 \\
Female gender & 0.52 & $(-1.5$ to 2.6$)$ & .618 \\
\hline White ethnicity & -2.73 & $(-5.3$ to -0.21$)$ & .034 \\
\hline History of tobacco smoking & -0.20 & $(-2$ to 1.6$)$ & .823 \\
Hypertension & 1.90 & $(-0.39$ to 4.2$)$ & .104 \\
Ca ${ }^{++}$channel blocker & 1.84 & $(-0.34$ to 4$)$ & .098 \\
\hline Diuretics & -1.89 & $(-3.8$ to -0.01$)$ & .049 \\
\hline Prior carotid endarterectomy & -5.55 & $(-10$ to -0.9$)$ & .019 \\
\hline CPB duration (per 60 min) & -1.28 & $(-2.4$ to -0.19$)$ & .022 \\
\hline
\end{tabular}

The final model was selected using backward selection based on Akaike Information Criterion from baseline predictors listed in Table 1. Demographic variables (age, gender, ethnicity, and smoking history) and study were kept in the model. Model $\mathrm{R}^{2}=0.1002$. $C I$, Confidence interval; $C P B$, cardiopulmonary bypass.

related to the optimal MAP. Nonwhite race was predictive of a higher optimal MAP, whereas preoperative diuretic use, prior carotid endarterectomy, and duration of $\mathrm{CPB}$ predicted a slightly lower optimal MAP. Overall, the model for predicting optimal MAP explained only a small portion of the variance in this metric.

Blood flow to the brain is kept constant over a range of blood pressures to ensure a steady supply of substrates commensurate with cerebral metabolic demand. Current practices of patient blood pressure management during CPB are based on the concept that global cerebral perfusion should not be compromised as long as MAP is maintained above the LLA. Support for this practice is derived from studies, now more than 2 decades old, which showed that $\mathrm{CBF}$ is independent of MAP during CPB to a MAP of 20 to $55 \mathrm{~mm} \mathrm{Hg} .^{4,5,7,29}$ In most of those studies, CBF was measured intermittently by ${ }^{133}$ xenon clearance methods, and the analysis involved pooled or paired comparisons of CBF versus MAP. In contrast, our investigations used continuous measurements of $\mathrm{CBF}$ autoregulation throughout $\mathrm{CPB}$ and included a larger number of patients.

Monitoring of cerebral autoregulation may provide a more precise approach for determining individualized MAP targets during $\mathrm{CPB}$, but this method requires specialized equipment and technical expertise. Our results suggest that the identified optimal MAP during CPB that we identified will reliably ensure perfusion within the autoregulation range for only $71 \%$ to $83 \%$ of patients. In others, the LLA will be above the identified population optimal MAP or the ULA will be below this value.

In our study, $16 \%$ of patients exhibited a pattern of impaired autoregulation in which Mx was greater than 0.4 at all MAPs. We have previously observed that this pattern is associated with risk for stroke. ${ }^{21}$ Even in this group, or for those whose MAP does not cross the LLA, an optimal MAP can be identified. Many centers modify empiric MAP targets for CPB on the basis of patient age. In our analysis, however, we found no association between optimal MAP and patient age. In this study, we found a significant relationship between the product of the magnitude and the duration that MAP was below the LLA and risk for stroke. In a prior study, we found a relationship between MAP below the LLA in the intensive care unit after cardiac surgery and release of the brain-specific injury biomarker glial fibrillary acidic protein. ${ }^{30}$ These data support a role of cerebral hypoperfusion in adverse neurologic complications after cardiac surgery. However, simply increasing MAP targets during CPB also could lead to adverse events. That is, we have found previously that the magnitude and duration that MAP is above the ULA during $\mathrm{CPB}$ is associated with postoperative delirium. ${ }^{20} \mathrm{~A}$ plausible explanation for this outcome is that cerebral hyperperfusion in the context of heightened systemic inflammation related to cardiac surgery with $\mathrm{CPB}$ might result in adverse cerebral events. ${ }^{31-33}$

Taken together, our data indicate the potential importance of maintaining MAP at a level that is neither below nor above the limits of autoregulation to optimize perfusion of the brain. In this study, we do not report on postoperative delirium or cognitive dysfunction. Moreover, our findings of a link between MAP below the LLA and stroke must be considered as an association. Whether targeting MAP on the basis of autoregulation metrics can lead to lower rates of stroke cannot be necessarily concluded from this study. We are currently conducting a prospectively randomized trial of autoregulation determined MAP versus the standard of care during CPB (National Institutes of Health R01HL092259). The primary end point of that ongoing study is a composite of adverse neurologic events, including stroke, brain magnetic resonance imaging-determined acute ischemic brain injury, and alterations in cognition from baseline.

\section{Study Limitations}

As with previous studies, we defined the limits of autoregulation as the MAP at which Mx increased to a value of 0.4 or greater. This value was associated with sepsisassociated delirium and mortality for patients with traumatic brain injury. ${ }^{22,34}$ Nonetheless, this cutoff is admittedly arbitrary and may not reflect the true lower limit, which could be an Mx greater than $0.3 .{ }^{35}$ Regardless, any dichotomous definition of the LLA based on Mx fails to consider that vasoactive compensatory responses to blood pressure changes may persist even when MAP is outside the confines of autoregulation. In addition to its retrospective design, our study has several limitations. Cerebral blood vessel reactivity might be affected by body temperature. Body temperature was not included in 
our analysis because we were unable to acquire this information in our data-acquisition scheme. Seven patients were excluded from analysis because of the lack of an identifiable TCD insonating window. However, because our sample size was above that required for identifying optimal MAP with precision, it seems unlikely that the exclusion of some patients for that reason led to an unintended bias in our results. Regardless, this finding underscores the limitations of TCD-based autoregulation monitoring that may preclude is routine adoption. Methods based on processing of near-infrared spectroscopy data hold promise as a clinically more feasible method for widespread cerebral autoregulation monitoring. ${ }^{17-21}$ Cerebral autoregulation measurements were based on CBF velocity in the middle cerebral arteries. Whether the LLA or optimal MAP thus identified applies to other major cerebral arterial systems is not known. Further, cerebral injury during cardiac surgery is primarily regional and may occur in vascular territories distal to an arterial stenosis or in the presence of small vessel disease. ${ }^{12}$ Autoregulation distal to a flow-limiting stenosis would be expected to be impaired and the CBF pressure dependent. Determining optimal MAP for areas of the brain without stenosis may still provide adequate MAP for proximal vascular territories that provide the "driving pressure" across the stenosed vessel. Finally, the patients in this study were mostly those at high risk for brain injury. Whether our findings are applicable to lower-risk patients is not known.

\section{CONCLUSIONS}

These data suggest that optimal MAP during CPB is $78 \pm 11 \mathrm{~mm} \mathrm{Hg}$, but in $17 \%$ and $29 \%$ of patients the LLA or ULA will be outside this range predisposing to unintentional cerebral hypoperfusion or hyperperfusion, respectively. Our finding of a relationship between MAP below the LLA during CPB and stroke supports a role of cerebral hypoperfusion and stroke. Development of clinical cerebral autoregulation monitors should be made a high priority to enable care providers the tools to individualize MAP during CPB.

\section{Webcast}

You can watch a Webcast of this AATS meeting presentation by going to: http://webcast.aats.org/2016/Video/ Monday/05-16-16_Room_337_1645_Hori-800.mp4.

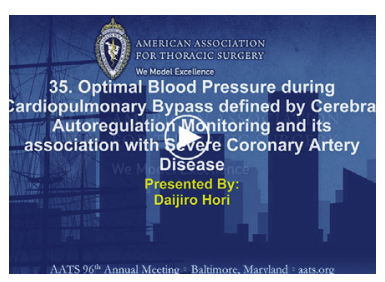

\section{Conflict of Interest Statement}

C.W.H. receives consulting fees, lecture honorarium, and research funding from Medtronics, Inc, Minneapolis, Minn. All other authors have nothing to disclose with regard to commercial support.

\section{References}

1. Gibbon JH Jr. Application of a mechanical heart and lung apparatus to cardiac surgery. Minn Med. 1954;37:171-85. passim.

2. Hannan EL, Wu C, Walford G, Culliford AT, Gold JP, Smith CR, et al. Drug-eluting stents vs coronary-artery bypass grafting in multivessel coronary disease. $N$ Engl J Med. 2008;358:331-41.

3. Abdallah MS, Wang K, Magnuson EA, Spertus JA, Farkouh MD, Fuster V, et al. Quality of life after PCI vs CABG among patients with diabetes and multivessel coronary artery disease: a randomized clinical trial. JAMA. 2013;310:1581-90.

4. Hogue CW Jr, Palin CA, Arrowsmith JE. Cardiopulmonary bypass management and neurologic outcomes: an evidence-based appraisal of current practices. Anesth Analg. 2006;103:21-37.

5. Murkin JM, Farrar JK, Tweed WA, McKenzie FN, Guiraudon G. Cerebral autoregulation and flow/metabolism coupling during cardiopulmonary bypass: the influence of PaCO2. Anesth Analg. 1987;66:825-32.

6. Schell RM, Kern FH, Greeley WJ, Schulman SR, Frasco PE, Croughwell ND, et al. Cerebral blood flow and metabolism during cardiopulmonary bypass. Anesth Analg. 1993;76:849-65.

7. Taylor KM. The hemodynamics of cardiopulmonary bypass. Semin Thorac Cardiovasc Surg. 1990;2:300-12.

8. Yamamoto M, Meyer JS, Sakai F, Yamaguchi F. Aging and cerebral vasodilator responses to hypercarbia: responses in normal aging and in persons with risk factors for stroke. Arch Neurol. 1980;37:489-96.

9. Schoof J, Lubahn W, Baeumer M, Kross R, Wallesch CW, Kozian A, et al. Impaired cerebral autoregulation distal to carotid stenosis/occlusion is associated with increased risk of stroke at cardiac surgery with cardiopulmonary bypass. J Thorac Cardiovasc Surg. 2007;134:690-6.

10. Inouye SK. Delirium in older persons. N Engl J Med. 2006;354:1157-65.

11. Moraca R, Lin E, Holmes JHT, Fordyce D, Campbell W, Ditkoff M, et al. Impaired baseline regional cerebral perfusion in patients referred for coronary artery bypass. J Thorac Cardiovasc Surg. 2006;131:540-6.

12. Gottesman RF, Sherman PM, Grega MA, Yousem DM, Borowicz LM Jr, Selnes OA, et al. Watershed strokes after cardiac surgery: diagnosis, etiology, and outcome. Stroke. 2006;37:2306-11.

13. Gottesman RF, Hillis AE, Grega MA, Borowicz LM Jr, Selnes OA, Baumgartner WA, et al. Early postoperative cognitive dysfunction and blood pressure during coronary artery bypass graft operation. Arch Neurol. 2007;64: 1111-4.

14. Floyd TF, Harris F, McGarvey M, Detre JA. Recurrence of stroke after cardiac surgery: insight into pathogenesis via diffusion-weighted and continuous arterial spin labeling perfusion magnetic resonance imaging. J Cardiothorac Vasc Anesth. 2007;21:106-9.

15. Czosnyka M, Brady K, Reinhard M, Smielewski P, Steiner LA. Monitoring of cerebrovascular autoregulation: facts, myths, and missing links. Neurocrit Care. 2009;10:373-86.

16. Joshi B, Ono M, Brown C, Brady K, Easley RB, Yenokyan G, et al. Predicting the limits of cerebral autoregulation during cardiopulmonary bypass. Anesth Analg. 2012;114:503-10.

17. Brady K, Joshi B, Zweifel C, Smielewski P, Czosnyka M, Easley RB, et al. Real-time continuous monitoring of cerebral blood flow autoregulation using near-infrared spectroscopy in patients undergoing cardiopulmonary bypass. Stroke. 2010;41:1951-6.

18. Ono M, Arnaoutakis GJ, Fine DM, Brady K, Easley RB, Zheng Y, et al. Blood pressure excursions below the cerebral autoregulation threshold during cardiac surgery are associated with acute kidney injury. Crit Care Med. 2013;41:464-71.

19. Ono M, Brady K, Easley RB, Brown C, Kraut M, Gottesman RF, et al. Duration and magnitude of blood pressure below cerebral autoregulation threshold during cardiopulmonary bypass is associated with major morbidity and operative mortality. J Thorac Cardiovasc Surg. 2014;147:483-9.

20. Hori D, Brown C, Ono M, Rappold T, Sieber F, Gottschalk A, et al. Arterial pressure above the upper cerebral autoregulation limit during cardiopulmonary bypass is associated with postoperative delirium. Br J Anaesth. 2014;113: 1009-17. 
21. Ono M, Joshi B, Brady K, Easley RB, Zheng Y, Brown C, et al. Risks for impaired cerebral autoregulation during cardiopulmonary bypass and postoperative stroke. Br J Anaesth. 2012;109:391-8.

22. Aries MJ, Czosnyka M, Budohoski KP, Steiner LA, Lavinio A, Kolias AG, et al Continuous determination of optimal cerebral perfusion pressure in traumatic brain injury. Crit Care Med. 2012;40:2456-63.

23. Brady KM, Mytar JO, Lee JK, Cameron DE, Vricella LA, Thompson WR, et al. Monitoring cerebral blood flow pressure autoregulation in pediatric patients during cardiac surgery. Stroke. 2010;41:1957-62.

24. Ono M, Zheng Y, Joshi B, Sigl JC, Hogue CW. Validation of a stand-alone near-infrared spectroscopy system for monitoring cerebral autoregulation during cardiac surgery. Anesth Analg. 2013;116:198-204.

25. McKhann GM, Grega MA, Borowicz LM Jr, Baumgartner WA, Selnes OA. Stroke and encephalopathy after cardiac surgery: an update. Stroke. 2006;37:562-71.

26. Steiner LA, Czosnyka M, Piechnik SK, Smielewski P, Chatfield D, Menon DK, et al. Continuous monitoring of cerebrovascular pressure reactivity allows determination of optimal cerebral perfusion pressure in patients with traumatic brain injury. Crit Care Med. 2002;733-8.

27. Steiner L, Coles J, Johnston A, Chatfield DA, Smielewski P, Fryer TD, et al. Assessment of cerebrovascular autoregulation in head-injured patients: a validation study. Stroke. 2003;34:2404-9.

28. Brady KM, Lee JK, Kibler KK, Smielewski P, Czosnyka M, Easley RB, et al. Continuous time-domain analysis of cerebrovascular autoregulation using near-infrared spectroscopy. Stroke. 2007;38:2818-25.

29. Govier AV, Reves JG, McKay RD, Karp RB, Zorn GL, Morawetz RB, et al. Factors and their influence on regional cerebral blood flow during nonpulsatile cardiopulmonary bypass. Ann Thorac Surg. 1984;38:592-600.

30. Hori D, Ono M, Rappold TE, Conte JV, Shah AS, Cameron DE, et al. Hypotension after cardiac operations based on autoregulation monitoring leads to brain cellular injury. Ann Thorac Surg. 2015;100:487-93.

31. Levy JH, Tanaka KA. Inflammatory response to cardiopulmonary bypass. Ann Thorac Surg. 2003;75:S715-20.

32. Rafiq MK, Connolly D, Randall M, Blank C. Cerebral hyperperfusion syndrome. Pract Neurol. 2014;14:64-6.

33. Schwartz RB. Hyperperfusion encephalopathies: hypertensive encephalopathy and related conditions. Neurologist. 2002;8:22-34.

34. Pfister D, Siegemund M, Dell-Kuster S, Smielewski P, Rüeggg S, Strebel SP, et al. Cerebral perfusion in sepsis-associated delirium. Crit Care. 2008;12:R63.

35. Sorrentino E, Budohoski KP, Kasprowicz M, Budohoski KP, Haubrich C, Smielewski P, et al. Critical thresholds for transcranial Doppler indices of cerebral autoregulation in traumatic brain injury. Neurocrit Care. 2011;14:188-93.

Key Words: cardiopulmonary bypass, cerebral autoregulation, blood pressure

\section{Discussion}

K. Shann (Boston, Mass). Intensive intraoperative cerebral monitoring or brain monitoring in 614 patients is a significant achievement. This work complements a large series of work from the group at Hopkins now focused on the topic of cerebral autoregulation during CPB. This study highlights the differences in the autoregulation range between patients with coronary artery disease and patients without and gives us insight into optimal targets for blood pressure management during $\mathrm{CPB}$.

Ten days ago we celebrated the 63rd anniversary of the heart-lung machine, and after all this time we still have limited data regarding the optimal blood pressure during CPB. So this work is also timely with the recent interest in creating strategies for goal-directed therapy for CPB.

I have 3 questions for you. You've identified optimal blood pressure targets of 80 and $75 \mathrm{~mm} \mathrm{Hg}$ for patients with and without coronary artery disease. In addition, your work identified an additional $14 \%$ of patients whose lower limit of autoregulation was higher than $75 \mathrm{~mm} \mathrm{Hg}$.

In some patients undergoing $\mathrm{CPB}$, it is challenging to maintain empirical target arterial pressures from our protocols, and elevated flow rates, elevated levels of vasopressors, or perhaps even transfusion is considered if not required.

I noticed in your methods you maintain CPB flow rates at 2.0 to $2.4 \mathrm{~L} / \mathrm{min} / \mathrm{m}^{2}$, which are consistent with common practice. I did not see any context in your article regarding the use of vasopressors to maintain a patient's pressure within their autoregulation range.

My first question is related to vasopressor use. We know from previous laboratory work that phenylephrine may redirect blood flow away from the bowel and muscle and direct it to the brain and the liver. In clinical practice, do we know whether strategies to maintain a patient's pressure within cerebral autoregulation range such as using increased pressors will ultimately improve outcome, or is it possible it causes other unwanted complications such as gut ischemia?

Dr Hori. We haven't looked at the other organ ischemia, but as I have shown in the previous slide, there is an association between the incidence of acute kidney injury (AKI) and the blood pressure management. In our institution, the majority of perfusionists change the pump flow first to control the blood pressure. Then, they will use phenylephrine to control the blood pressure.

Our previous studies have shown that blood pressures below the optimal MAP or below the low limit of autoregulation were associated with AKI, which means that if the blood pressure is too low, the incidence of AKI would increase. But we didn't look at the dosage of phenylephrine in association with AKI. That is something we need to look at.

The studies show that the blood pressures below the optimal MAP or below the low limit of autoregulation were associated with AKI, which means that if the blood pressure is too low, the incidence of AKI would go up. But we didn't look at the dosage of phenylephrine in association with an AKI, so that's something that we need to look at.

K. Shann. To follow with that question, in 1995 the Cornell group randomized 248 patients undergoing CPB to a blood pressure of 50 to $60 \mathrm{~mm} \mathrm{Hg}$ or 80 to $100 \mathrm{~mm}$ $\mathrm{Hg}$. They reported improved outcomes in the high pressure group; however, this work received scrutiny in part because of the high stroke rate in the low pressure group of $7.2 \%$.

Other work your group has done, which was referenced your article, to study the association between autoregulation range, and outcome has been observational without measurement of interventions. Is it time to perform a randomized trial, kind of like the Cornell group did to 
answer the question do interventions to maintain a patient's pressure within the autoregulation range during $\mathrm{CPB}$ improve outcome? In other words, do we need to do that randomized control trial now using your work as the basis?

Dr Hori. This is another good point, and we are doing a randomized trial at Hopkins right now. If the patient is randomized to treatment, we will tell the perfusionist and the anesthesiologist the optimal MAP. They will try to control the pressure at that optimal MAP, and we're going to look at the results.

K. Shann. Do you have an algorithm for the interventions?

Dr Hori. No. That's one of the limitations we have.

K. Shann. The optimal MAP targets you have identified will keep approximately $75 \%$ to $80 \%$ of patients within their autoregulation range, which leaves $20 \%$ to $25 \%$ of patients out of their autoregulation range.

In the current study, you used TCD combined with MAP put into a data housing unit that calculates an $\mathrm{Mx}$ and determines the upper and lower limits of autoregulation. For the majority of us in the room, that's not practical in routine clinical practice.

Your group also has published work using an investigational prototype device that you refer to as the nearinfrared spectroscopy cerebral autoregulation monitor, which I don't believe has ever come to market. You more recently published material on the use of an ultrasound tag near-infrared spectroscopy autoregulation monitor that I believe is FDA approved. So my question is how close are we to having a user-friendly and clinically practical technology to monitor cerebral autoregulation during CPB?

Dr Hori. I think cerebral oximetry is easy to use. We just have to put the sensor stickers on the patient's forehead. If you use the ICM software, all we need to do is just plug in the near-infrared spectroscopy signals into the ICM computer, and it will calculate the cerebral oximetry index for you. It's a very easy system to use. It's not that complicated, as I stated in the article. It's just 1 laptop and 1 INVOS (Medtronic/Covidien, Boulder, Colo), and you will have the data there.

K. Shann. So there is an application that....

Dr Hori. The ICM software calculates everything for you, right? The software is the most important thing.

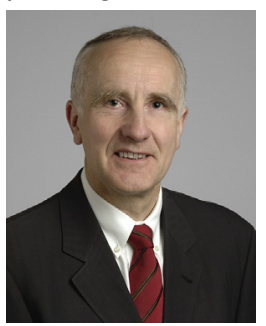

Dr G. Pettersson (Cleveland, Ohio). This is an important topic. How do you distinguish between the global and local cerebral perfusion issues? Do we have any other ways of monitoring whether the brain is adequately perfused and at risk? What is the "reasonably safe underperfusion limit"?

Dr Hori. You mean for the monitoring?

Dr Pettersson. How far below the autoregulation limit can you go before you get damage to the brain?

Dr Hori. I'm not really sure about that. We are not sure if there is a cutoff value. But our studies have shown that the magnitude of blood pressure management outside the autoregulation range is positively correlated with the incidence of AKI and neurologic complications.

Dr Pettersson. Is there any way of studying it in advance so we could know?

Dr Hori. Know the limit you mean?

Dr Pettersson. So we could know the autoregulation in the individual patient before he/she goes to the operating room.

Dr Hori. It is difficult to predict autoregulation range without monitoring. To measure cerebral autoregulation using this system, you need data from a wide range of blood pressure levels to draw the cerebral autoregulation curve. But now, the ICM software can predict the optimal MAP by algorithm. So even if you only have few data, it will be able to draw that cerebral autoregulation curve by algorithm. 


\section{APPENDIX. SUPPLEMENTAL MATERIAL}

More details can be found at: http://www.neurosurg.cam.ac. uk/pages/ICM/about.php.

\section{AUTOREGULATION SIGNAL ACQUISITION AND PROCESSING METHODS}

TCD monitoring (DWL, Compumedics DWL, El Paso, Tex) of the right and left middle cerebral arteries was performed with two $2.5-\mathrm{MHz}$ transducers fitted on a headband and positioned over the temporal bone windows to obtain bilateral continuous measurement of baseline velocity. Depth of insonation was varied between 35 and $52 \mathrm{~mm}$ until representative spectral middle cerebral artery flow is identified, and then the transducers are locked in that position. Arterial pressure data (from an indwelling cannula placed for clinical purposes) were obtained from the operating room hemodynamic monitor via the analog output port. The arterial blood pressure data and the TCD signals were sampled at $58 \mathrm{~Hz}$ with an analog-to-digital converter and then imported into a laptop computer using ICM+ software (University of Cambridge, Cambridge, United Kingdom). ${ }^{\text {E1-E7 }}$ This proprietary software collects and integrates high-resolution, multimodal data for real-time analysis of intracranial pressure, arterial pressure, brain oxygenation, blood flow, and other signals allowing for calculation of various physiologic indices, including autoregulation metrics (https://www.enterprise. cam.ac.uk/opportunities/icm-software-for-brain-monitoringin-neurological-intensive-care-research/).

Blood pressure and TCD signals are time-integrated as nonoverlapping 10-second mean values, equivalent to applying a moving average filter with a 10 -second time window and resampling at $0.1 \mathrm{~Hz}$. This operation eliminates high-frequency noise from the respiratory and pulse frequencies, according to the Nyquist theorem, allowing detection of oscillations and transients that occur below $0.05 \mathrm{~Hz}$. A continuous, moving Pearson's correlation coefficient is calculated between MAP and TCD cerebral blood flow velocity, rendering the variable $\mathrm{Mx}$. Consecutive, paired, 10-second averaged values from 300 -second duration are used for each calculation, incorporating 30 data points as we have reported. ${ }^{\mathrm{E}, \mathrm{E} 9} \mathrm{Mx}$ values for each patient are placed into $5 \mathrm{~mm} \mathrm{Hg}$ MAP bins and displayed on the laptop computer (Figure E1). When MAP is within the limits of CBF, autoregulation Mx approaches zero; when MAP is outside the limits of autoregulation, $\mathrm{Mx}$ approaches 1, indicating that $\mathrm{CBF}$ is blood pressure dependent.

On the basis of our prior studies, we designate the LLA as the highest blood pressure associated with $\mathrm{Mx} 0.4$ or greater. These values are within the range found to be associated with poor outcome after traumatic brain injury and adverse outcomes after cardiac surgery. ${ }^{\text {E10-E13 }}$ In approximately $20 \%$ of patients, impaired autoregulation is observed when $\mathrm{Mx}$ is 0.4 or greater at all MAPs during CPB. An attenuated autoregulation plateau is usually observed. Thus, the "optimal" MAP, defined as the MAP with the lowest Mx, at this point is observed in patients with functional and impaired autoregulation. As blood pressure varies during the usual course of surgery, including during the initiation of $\mathrm{CPB}$, no specific interventions are needed to establish autoregulation indices.

\section{E-References}

E1. Steiner L, Coles J, Johnston A, Chatfield D, Smielewski P, Fryer T, et al. Assessment of cerebrovascular autoregulation in head-injured patients: a validation study. Stroke. 2003;34:2404-9.

E2. Lang EW, Mehdorn HM, Dorsch NW, Czosnyka M. Continuous monitoring of cerebrovascular autoregulation: a validation study. J Neurol Neurosurg Psychiatry. 2002;72:583-6.

E3. Steiner LA, Czosnyka M, Piechnik SK, Smielewski P, Chatfield D, Menon DK, et al. Continuous monitoring of cerebrovascular pressure reactivity allows determination of optimal cerebral perfusion pressure in patients with traumatic brain injury. Crit Care Med. 2002;30:733-8.

E4. Reinhard M, Roth M, Muller T, Guschlbauer B, Timmer J, Czosnyka M, et al. Effect of carotid endarterectomy or stenting on impairment of dynamic cerebral autoregulation. Stroke. 2004;35:1381-7.

E5. Minhas PS, Smielewski P, Kirkpatrick PJ, Pickard JD, Czosnyka M. Pressure autoregulation and positron emission tomography-derived cerebral blood flow acetazolamide reactivity in patients with carotid artery stenosis. Neurosur gery. 2004;55:63-8.

E6. Reinhard M, Roth M, Guschlbauer B, Harloff A, Timmer J, Czosnyka M, et al. Dynamic cerebral autoregulation in acute ischemic stroke assessed from spontaneous blood pressure fluctuations. Stroke. 2005;36:1684-9.

E7. Lavinio A, Schmidt E, Haubrich C, Smielewski P, Pickard JD, Czosnyka M Noninvasive evaluation of dynamic cerebrovascular autoregulation using Finapres plethysmograph and transcranial Doppler. Stroke. 2007;38:402-4.

E8. Brady KM, Lee JK, Kibler KK, Smielewski P, Czosnyka M, Easley RB, et al. Continuous time-domain analysis of cerebrovascular autoregulation using near-infrared spectroscopy. Stroke. 2007;38:2818-25.

E9. Brady K, Joshi B, Zweifel C, Smielewski P, Czosnyka M, Easley B, et al. Real time continuous monitoring of cerebral blood flow autoregulation using nearinfrared spectroscopy in patients undergoing cardiopulmonary bypass. Stroke. 2010;41:1951-6.

E10. Blauth C, Schulenberg W, McCartney A, Taylor K, Loop F. Retinal microvascular studies in vivo with fluorescein angiography. J Thorac Cardiovasc Surg. 1988;95:668-76.

E11. Schell R, Kern F, Greeley W, Schulman S, Frasco P, Croughwell N, et al. Cerebral blood flow and metabolism during cardiopulmonary bypass. Anesth Analg. 1993; 76:849-65.

E12. Ono M, Arnaoutakis GJ, Fine DM, Brady K, Easley RB, Zheng Y, et al. Blood pressure excursions below the cerebral autoregulation threshold during cardiac surgery are associated with acute kidney injury. Crit Care Med. 2013;41: 464-71.

E13. Ono M, Brady K, Easley R, Brown C, Kraut M, Gottesman R, et al. Duration and magnitude of blood pressure below cerebral autoregulation threshold during cardiopulmonary bypass is associated with major morbidity and operative mortality. J Thorac Cardiovasc Surg. 2014;147:483-9. 


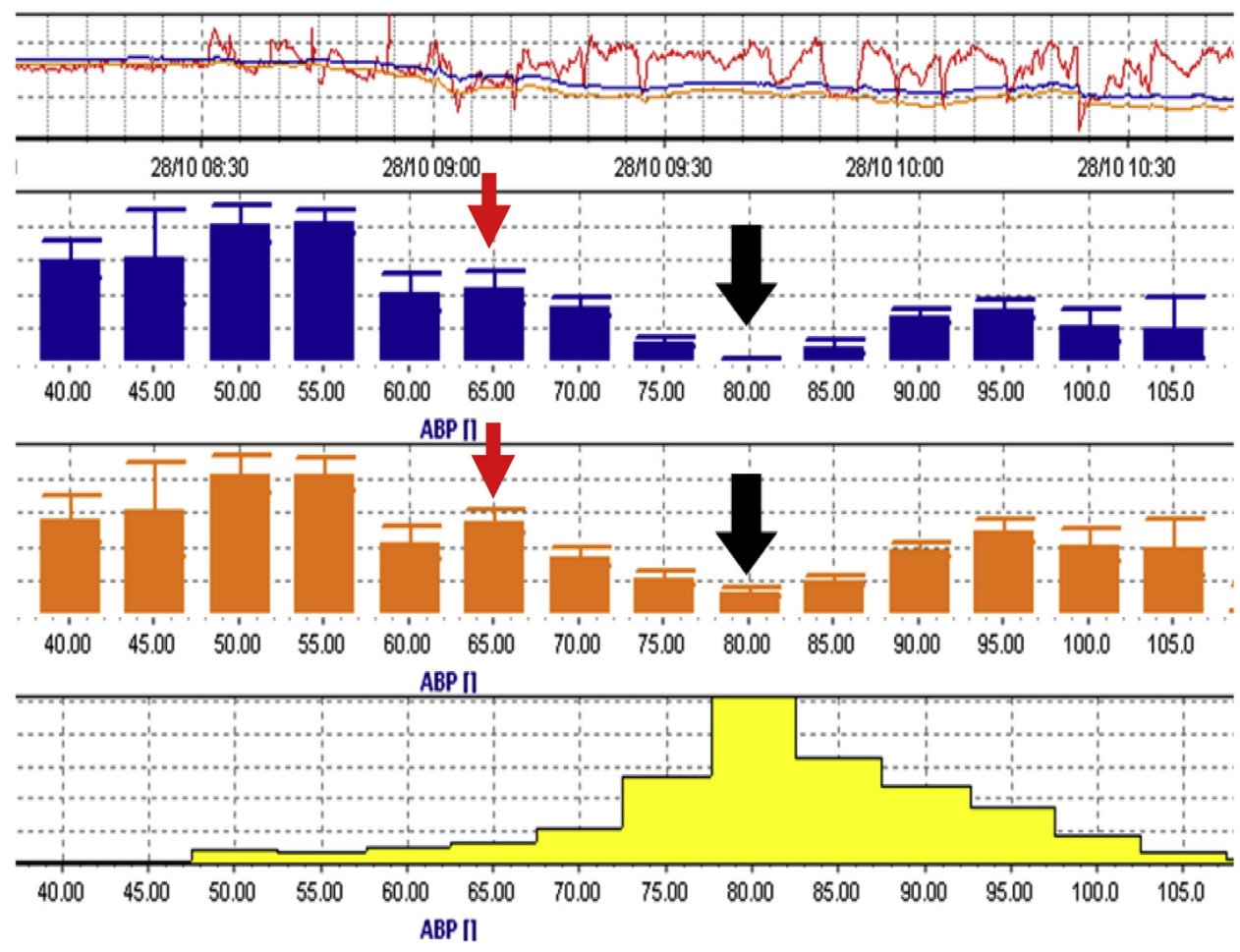

FIGURE E1. Graph of autoregulation data obtained in the operating room during CPB. The top graph is the time series of blood pressure. The middle 2 bar graphs represent autoregulation data from the left and right sides, respectively, placed into $5 \mathrm{~mm} \mathrm{Hg} \mathrm{ABP} \mathrm{bins.} \mathrm{The} \mathrm{bottom} \mathrm{histogram} \mathrm{represents} \mathrm{the}$ percentage of the time of the recording spent at each ABP bin. The autoregulation variable is a dimensionless correlation coefficient between CBF velocity and $\mathrm{ABP}(\mathrm{Mx})$. An Mx approaching 1 represents impairment of autoregulation, and Mx close to zero represents functional autoregulation. The red short arrow represents the lower limit of autoregulation defined in this analysis as that ABP with Mx increases from less than 0.4 to 0.4 or greater. The thick black arrow indicates optimal $\mathrm{ABP}$ defined as that $\mathrm{ABP}$ with the lowest Mx. $A B P$, Arterial blood pressure. 